\title{
Narcolepsy Associated with Pandemrix Vaccine
}

\author{
Tomi Sarkanen ${ }^{1,2} \cdot$ Anniina Alakuijala $^{2,3} \cdot$ Ilkka Julkunen $^{4}$ - Markku Partinen ${ }^{2,5}$
}

Published online: 1 June 2018

(C) Springer Science+Business Media, LLC, part of Springer Nature 2018

\begin{abstract}
Purpose of Review After the connection between AS03-adjuvanted pandemic H1N1 vaccine Pandemrix and narcolepsy was recognized in 2010, research on narcolepsy has been more intensive than ever before. The purpose of this review is to provide the reader with current concepts and recent findings on the Pandemrix-associated narcolepsy.

Recent Findings After the Pandemrix vaccination campaign in 2009-2010, the risk of narcolepsy was increased 5- to 14-fold in children and adolescents and 2- to 7-fold in adults. According to observational studies, the risk of narcolepsy was elevated for 2 years after the Pandemrix vaccination. Some confounding factors and potential diagnostic biases may influence the observed narcolepsy risk in some studies, but it is unlikely that they would explain the clearly increased incidence in all the countries where Pandemrix was used. An increased risk of narcolepsy after natural H1N1 infection was reported from China, where pandemic influenza vaccination was not used. There is more and more evidence that narcolepsy is an autoimmune disease. All Pandemrixassociated narcolepsy cases have been positive for HLA class II DQB ${ }^{*} 06: 02$ and novel predisposing genetic factors directly linking to the immune system have been identified. Even though recent studies have identified autoantibodies against multiple neuronal structures and other host proteins and peptides, no specific autoantigens that would explain the disease mechanism in narcolepsy have been identified thus far.

Summary There was a marked increase in the incidence of narcolepsy after Pandemrix vaccination, especially in adolescents, but also in young adults and younger children. All vaccine-related cases were of narcolepsy type 1 characterized by hypocretin deficiency in the central nervous system. The disease phenotype and the severity of symptoms varied considerably in children and adolescents suffering from Pandemrix-associated narcolepsy, but they were indistinguishable from the symptoms of idiopathic narcolepsy. Narcolepsy type 1 is most likely an autoimmune disease, but the mechanisms have remained elusive.
\end{abstract}

Keywords Narcolepsy $\cdot$ H1N1 vaccination $\cdot$ Vaccines $\cdot$ Pandemrix $\cdot$ Hypocretin $\cdot$ Orexin

\section{Introduction}

Narcolepsy is a chronic hypersomnia syndrome characterized by excessive daytime sleepiness, disturbed sleep pattern, and REM sleep parasomnias such as hypnagogic hallucinations and sleep paralyzes. In the most recent (3rd version)

This article is part of the Topical Collection on Sleep

\section{Markku Partinen}

markpart@me.com; markku.partinen@helsinki.fi

Tomi Sarkanen

tsarkane@gmail.com

Anniina Alakuijala

anniina.alakuijala@hus.fi

Ilkka Julkunen

ilkka.julkunen@utu.fi
International Classification of Sleep Disorders (ICSD-3), the disease is divided into two different subcategories, narcolepsy type 1 and type 2 (Table 1) [1]. Narcolepsy type 1 (NT1) is likely an immune-mediated disease caused by the destruction of hypocretin-producing neurons in the lateral hypothalamus resulting in hypocretin deficiency in the central nervous
1 Department of Neurology, Tampere University Hospital, Tampere, Finland

2 Department of Clinical Neurosciences, University of Helsinki, Helsinki, Finland

3 HUS Medical Imaging Center, Department of Clinical Neurophysiology, Helsinki University Central Hospital, Helsinki, Finland

4 Institute of Biomedicine, University of Turku, Turku, Finland

5 Helsinki Sleep Clinic, Vitalmed Research Center, Helsinki, Finland 
Table 1 Diagnostic criteria of types 1 and 2 narcolepsy (ICSD-3) [1]

\section{NARCOLEPSY TYPE 1}

Criteria A and B must be met

A. The patient has daily periods of irrepressible need to sleep or daytime lapses into sleep occurring for at least three months. ${ }^{1}$

B. The presence of one or both of the following:

1. Cataplexy (as defined under Essential Features) and a mean sleep latency of $\leq 8$ minutes and two or more sleep onset REM periods (SOREMPs) on an MSLT performed according to standard techniques. A SOREMP (within 15 minutes of sleep onset) on the preceding nocturnal polysomnogram may replace one of the SOREMPs on the MSLT. $^{2}$

2. CSF hypocretin- 1 concentration, measured by immunoreactivity, is either $\leq 110 \mathrm{pg} / \mathrm{mL}$ or $<1 / 3$ of mean values obtained in normal subjects with the same standardized assay.

\section{NARCOLEPSY TYPE 2}

Criteria A-E must be met

A. The patient has daily periods of irrepressible need to sleep or daytime lapses into sleep occurring for at least three months.

B. A mean sleep latency of $\leq 8$ minutes and two or more sleep onset REM periods (SOREMPs) are found on a MSLT performed according to standard techniques. A SOREMP (within 15 minutes of sleep onset) on the preceding nocturnal polysomnogram may replace one of the SOREMPs on the MSLT.

C. Cataplexy is absent. ${ }^{3}$

D. Either CSF hypocretin-1 concentration has not been measured or CSF hypocretin- 1 concentration measured by immunoreactivity is either $>110 \mathrm{pg} / \mathrm{mL}$ or $>1 / 3$ of mean values obtained in normal subjects with the same standardized assay. ${ }^{4}$

E. The hypersomnolence and/or MSLT findings are not better explained by other causes, such as insufficient sleep, obstructive sleep apnea, delayed sleep phase disorder, or the effect of medication or substances or their withdrawal.

\section{ICSD-3 International Classification of Sleep Disorders, 3rd edition}

${ }^{1}$ In young children, narcolepsy may sometimes present as excessively long night sleep or as resumption of previously discontinued daytime napping

${ }^{2}$ If narcolepsy type I is strongly suspected clinically but the MSLT criteria of B1 are not met, a possible strategy is to repeat the MSLT

${ }^{3}$ If cataplexy develops later, then the disorder should be reclassified as narcolepsy type 1

${ }^{4}$ If the CSF Hcrt- 1 concentration is tested at a later stage and found to be either $\leq 110 \mathrm{pg} / \mathrm{mL}$ or $<1 / 3$ of mean values obtained in normal subjects with the same assay, then the disorder should be reclassified as narcolepsy type 1

system (CNS). Over $98 \%$ of the NT1 patients have a predisposing genetic background, positivity for HLA DQB1*06:02 allele. Cataplexy, sudden loss of muscle tone triggered by emotions, is a common symptom in these patients. In narcolepsy type 2 (NT2), hypocretin levels are normal and cataplexy is absent. The etiology of NT2 is presently not known.

Narcolepsy is a rare disease. A remarkable increase in the incidence of NT1 was seen after the H1N1 vaccination campaign in the countries where the Pandemrix vaccine was used $[2 \bullet \bullet, 3]$. Pandemrix-related narcolepsy with a clearly recognized environmental trigger increased global research activities on the pathophysiological mechanism of narcolepsy but crucial observations explaining the underlying disease mechanisms have so far not been identified.

\section{Epidemiology-How Big Was the Risk of Pandemrix-Related Narcolepsy?}

The most recent pandemic, called "swine flu," was caused by a new reassortant H1N1-type influenza A virus, which appeared first in Mexico and the USA in March 2009. The number of laboratory-confirmed cases increased rapidly and the new pandemic virus spread to many other countries via people traveling. By June 2009, the WHO had already declared that a new pandemic had started. The previous H1N1 pandemic in 1918-1919 ("Spanish flu") was a devastating disease with a high mortality rate resulting in 50 to even 100 million deaths worldwide. In 2009, an early observational study from Mexico indicated that ca. $6.5 \%$ of 900 hospitalized H1N1 infection patients were critically ill and, of those, $41 \%$ died [4]. The mortality seemed to be high especially in children, young adults, and pregnant women, in contrast to the seasonal influenza epidemics. Therefore, initially, the first influenza pandemic of the twenty-first century appeared to be very severe and there was a substantial need for the rapid development of an efficient pandemic vaccine.

Eight different pandemic vaccines were used in Europe, with a coverage of at least 46 million people. Five of these vaccines had no adjuvant, while two vaccines included MF59 as an adjuvant and one vaccine, namely Pandemrix, had AS03 as an adjuvant. Adjuvants increase the immunogenicity of antigens, thus allowing the use of lower amounts of immunogens in vaccines for efficient induction of protective immunity. Pandemrix was the most widely used vaccine in Europe with more than 30.5 million administered doses [5]. Another AS03-adjuvanted vaccine, Arepanrix, was used particularly in Canada. Globally, over 90 million doses of AS03-adjuvanted $\mathrm{H} 1 \mathrm{~N} 1$ vaccines were given in different countries [6]. In the USA, over 90 million doses of pandemic H1N1 vaccines were administered in 2009-2010, but they were all non-adjuvant vaccines.

The first signals of the increased number of narcolepsy cases after H1N1 vaccination campaigns came from Finland, Sweden, and France $[7 \bullet \bullet, 8,9]$. Increased incidence of narcolepsy was later found in Norway, the UK, Ireland, and Germany. The vaccination coverage with Pandemrix was high in all of these countries [10-13]. The risk was first noted in children and adolescents, and later also in young adults [13-16]. The time period for increased risk is still unclear. Finnish and Swedish epidemiological (observational) studies have reported that the time window of an increased risk extends to 2 years after the vaccination with Pandemrix $[15,17]$. The reported relative risk of narcolepsy during the first year after the vaccination varied from 2 to 25 in children and 
adolescents, and 2 to 9 in adults. In a recent meta-analysis, we found a 5- to 14-fold increased risk of Pandemrix-related narcolepsy in children and adolescents, and a 2- to 7-fold increased risk in adults $[2 \bullet \bullet]$.

The magnitude of observed risk is partly dependent on the analytical methods and the criteria concerning how the narcolepsy cases were identified. For example, in the Swedish registry study, where there was no case ascertainment and no medical record review [15], the risk was lower than in a previous cohort study [8]. Nonetheless, this study also demonstrated an increase in the incidence of narcolepsy in young adults during the second post-vaccination year. It is worth noting that the 2-year risk window is based on epidemiological data. The biologic risk window is not known. In the first series of patients with Pandemrix-related narcolepsy, the median delay from time of vaccination to onset of narcolepsy was 42 days ( 0 to 242 days) [18••]. However, it is important to note that a maximal biologic length of a temporal relationship between the onset of narcolepsy and a specific immunological trigger, such as a viral infection or a vaccination, has not been defined.

\section{Controversies in Epidemiological Studies-Is the Association True?}

The main limitation in the observational studies is that they are unable to prove a direct causal link between the trigger(s) and the disease. They are also prone to various biases such as ascertainment and recall bias and other confounding factors. It has been speculated that a natural H1N1 influenza infection per se would have been an important confounding factor contributing to an increased incidence of narcolepsy [19-21]. A 3 -fold increased risk was reported in Beijing and Shanghai areas, where pandemic $\mathrm{H} 1 \mathrm{~N} 1$ vaccines were not used, during the post-pandemic period $[22 \bullet, 23,24]$. These findings suggest a temporal association between the H1N1 epidemic peak and a peak in new narcolepsy cases 3 to 6 months after the influenza epidemic. However, these results have not been replicated in the neighboring countries or in any other populations $[2 \bullet \bullet, 25]$. The vaccination campaign and H1N1 influenza epidemic occurred almost simultaneously, and, for example, in Norway and Finland, less than $10 \%$ of the population had been vaccinated prior to the peak of the pandemic [26]. Another study proposed that more than $50 \%$ of the vaccinated individuals in Norway could already have been infected with the H1N1 virus prior to vaccinations [27]. Conversely, practically, no serological evidence of natural 2009 pandemic H1N1 virus infection was found in Finnish narcolepsy patients [28]. The manufacturer of Pandemrix, GlaxoSmithKline, has criticized the latter study for its low specificity and the long interval between the vaccination or infection and collection of the serum samples [29].
Diagnostic bias may be involved if vaccinated subjects were more likely to be diagnosed as narcolepsy cases than unvaccinated subjects. There is a possibility that primary health care practitioners referred vaccinated subjects to special sleep clinics more often than unvaccinated children/adolescents. However, this seems unlikely, since narcolepsy, whether associated with vaccine or not, is usually an incapacitating disease clearly affecting the quality of life. The unequivocal diagnostic criteria also reduce the risk of diagnostic ascertainment bias.

There is also a possibility for recall bias. This could be caused by a memory bias of the correct onset time of narcolepsy symptoms and their relation to the vaccination time. Memory bias could happen involuntarily but also knowingly after the increased media and public awareness of the connection between $\mathrm{H} 1 \mathrm{~N} 1$ vaccination and narcolepsy in the hope of a monetary reimbursement. However, many observational studies used the first health care contact as an index date and the results were similar between different study groups and countries. Proven association of Pandemrix vaccination and narcolepsy in the countries where media attention and awareness of the association were lower (England, France, Ireland, and Germany) also makes the recall bias more unlikely. Some controversies and unsolved issues are summarized in Table 2.

\section{Pathophysiology_What Is Narcolepsy and Why Did H1N1 Vaccination Trigger It?}

The hallmark of NT1 is hypocretin deficiency. Hypocretin, also called orexin, is a neuropeptide independently discovered by two separate research groups, hence the two different names $[33,34]$. Soon after these findings, the lack of a functional hypocretin system as an etiological factor in narcolepsy in humans was recognized in immunohistochemical studies [35].

All Pandemrix-related, verified, and true narcolepsy cases have been of NT1. Although some people may have developed excessive daytime sleepiness along with a NT2 phenotype without hypocretin loss after Pandemrix vaccination, the correlation is currently considered only coincidental. Biological plausibility between immunological triggers such as vaccination and NT2 is lacking.

The pathophysiological events leading to the destruction of hypothalamic hypocretin-producing cells in NT1 are presently unclear. It has been speculated that especially cell-mediated autoimmunity, but also autoantibodies against neuronal structures, or cytotoxicity caused by cytokines and inflammatory cells in CNS could lead to the destruction of hypocretinproducing neurons $[3,36]$. In addition to immune-mediated destruction of hypocretin neurons, secondary narcolepsy has been described, for instance, in patients with rare inherited disorders, brain tumors, traumatic brain injury, and demyelinating disorders which lie outside the scope of this review [37]. 
Table 2 Controversies and unsolved issues in Pandemrixrelated narcolepsy

Factors proving a link between Pandemrix vaccine and narcolepsy

Strong and consistent epidemiological connection

Immunological connection

Factors affecting robustness of association

Possible biases in observational studies

Confounding by natural H1N1 infection

Ascertainment, information and recall bias

Missing pathophysiological link

Missing autoantibodies
Increased incidence of narcolepsy shown separately by different study groups and authorities in all the countries where the Pandemrix vaccine was used on a large scale $[2 \bullet \bullet, 7 \bullet \bullet, 8-17]$.

Higher immune response against H1N1 virus nucleoprotein in narcoleptic patients than in healthy controls $[30 \bullet \bullet]$.

Cross-reactivity between influenza NP and human hypocretin receptor 2 [31].

Increased incidence of narcolepsy in China not related to vaccination $[22 \cdot, 23]$.

Data showing H1N1 virus is capable of entering into the hypothalamus via the olfactory nerve and causing narcolepsy-like sleep-wake disruption in immune-compromised rat [32].

Concomitant circulating H1N1 infection during the vaccination campaign [27].

Lack of validation of cases in some studies $[2 \bullet \bullet, 7 \bullet \bullet, 8-21]$.

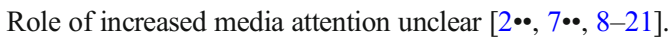

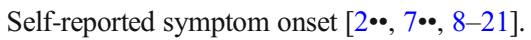

Possible autoantibodies against different neuronal structures have a low specificity for narcolepsy and they are also found, though to a lesser extent, in other sleep disorders or healthy controls.
NT1 is tightly associated with HLA class II allele DQB1*06:02. More than $98 \%$ of NT1 patients are positive for this allele, making it almost a prerequisite for the disease. However, this allele is very common in Western countries and $20-30 \%$ of the general population is positive for this allele. The relative risk among individuals positive for DQB $1 * 06: 02$ is ca. 250 times higher than among those individuals who do not have this allele [38•]. The DQB1*06:02 HLA molecule forms homodimers or heterodimers with another HLA class II molecule, DQA1*01:02, which also contributes to the relative risk of NT1 susceptibility [39, 40].

HLA class II molecules play a pivotal role in antigen presentation and cell-mediated immunity. The link between HLA DQB1*06:02 allele and NT1 is highly indicative of an autoimmune background in the disease pathogenesis. Also, HLA class I alleles and HLA-DP molecules seem to have an independent role in susceptibility for narcolepsy $[41 \bullet, 42 \bullet]$. There are also multiple protective alleles that reduce the risk of NT1. In the study by Ollila and coworkers, the most protective heterodimer was HLA-DPA1*01:03-DPB1*04:02 [41•]. HLA-DP loci are known to have a role in autoimmune diseases such as multiple sclerosis and type 1 diabetes. Association with HLA class I alleles also implicates the possibility of the involvement of cell-mediated cytotoxicity in narcolepsy.
An association with triggering environmental factors such as $\mathrm{H} 1 \mathrm{~N} 1$ vaccination, $\mathrm{H} 1 \mathrm{~N} 1$ virus infection, and streptococcal infections further strengthens the autoimmune hypothesis in the pathogenesis of NT1 [3, 43]. Nevertheless, no peptides associated with DQB1*06:02 have been identified; thus, there is no identification of cross-reactive peptides between microbial pathogens (such as influenza virus or Streptococcus pyogenes) and human autoantigens, especially those that could be specific for hypocretin-producing neurons.

In addition, gene polymorphisms in several genes such as carnitine palmitoyl transferase 1B (CPT1B) and choline kinase $\mathrm{B}$ (CHKB) have been linked to narcolepsy. In some studies, an increased narcolepsy risk was associated with T cell receptor $\alpha$ chain gene (TCRA), cathepsin H (CTSH), and purinergic receptor subtype 2Y11 (P2RY11) (reviewed in [3]). However, the contribution of gene polymorphisms and other genes apart from HLA class II genes in narcolepsy susceptibility is relatively low. It is noteworthy that most of the genes associated with increased narcolepsy risk are involved in the regulation of the immune system. Thus, these findings further support the immune-mediated disease mechanisms of NT1.

Moreover, a link between narcolepsy and H1N1 infection has been seen in immunocompromised mice. Kristensson and coworkers infected recombinant activating gene 1-deficient 
mice, which lacked T and B cells, with the H1N1 influenza A virus and demonstrated that the infection spread to CNS and targeted hypocretin-producing neurons in the hypothalamus, which led to a narcolepsy-like syndrome in these animals [32]. However, most Finnish patients with Pandemrix-associated narcolepsy were shown not to have antibodies against nonstructural protein 1 (NS1) of the pandemic H1N1 influenza virus, making it unlikely that the 2009 pandemic H1N1 virus infection was the causative factor in the development of narcolepsy in these patients [28]. NS1 is produced in the host during the infection and it is not present in influenza vaccines; thus, anti-NS1 antibodies are found only in humans who suffered a natural influenza A virus infection. This does not rule out the possibility of a microbial infection being able to trigger the onset of narcolepsy, but at least in our patients with Pandemrix-associated narcolepsy, we could not identify any other environmental factors apart from the Pandemrix vaccine that was associated with narcolepsy $[18 \bullet \bullet, 28]$.

In addition to a genetic link with factors regulating cellmediated immunity and potential narcolepsy-triggering infections, many groups have identified higher frequencies of autoantibodies among narcoleptic patients. These antibodies include anti-Tribbles homolog 2 and anti-ganglioside antibodies, as well as antibodies against various neuronal structures, neurotransmitters, and neuron-specific molecules such as neurexin-1 [44, 45]. There is also evidence that hypocretin receptor 2 may be the target for autoantibodies [31].

Newly diagnosed narcolepsy patients have been shown to have a higher frequency of anti-Tribbles 2 (TRIB2) homolog antibodies than control individuals [46-49]. The Tribbles family of proteins is protein kinase homologs involved in cell growth regulation, but the precise function of TRIB2 homolog pseudokinase is not known. Immunoglobulins from narcolepsy patients positive for anti-TRIB2 antibodies cause loss of hypothalamic hypocretin neurons and sleep disturbances when injected into mice [48]. In addition, TRIB2immunized rats displayed autoantibody formation and staining of hypothalamic structures, including hypocretin neurons. However, the study failed to demonstrate a direct connection between anti-TRIB2 antibodies and destruction of hypocretin neurons, suggesting that the development of anti-TRIB2 antibodies may be a consequence of neuronal damage rather than the cause [50].

Autoantibodies against neuronal gangliosides have been linked to some neurological diseases such as the GuillainBarré syndrome [51]. Recently, Saariaho and coworkers demonstrated that children and adolescent with Pandemrixassociated narcolepsy have a higher frequency of antihuman ganglioside GM3 antibodies [45]. An older study failed to show an association of anti-ganglioside antibodies and narcolepsy [52], but in that study, the ganglioside pattern used for autoantibody detection was limited compared to that in the more recent study. The role of anti-ganglioside antibodies in the pathogenesis of narcolepsy remains unclear as it is not known if they contribute to the destruction of hypocretin neurons or emerge as a consequence of the neuronal damage.

Additional information on the presence of autoantibodies against neuronal structures in Pandemrix-associated narcolepsy was obtained in an immunohistochemical study in rat brain sections [53•]. This study demonstrated that as many as $27 \%$ of patients had autoantibodies against neuronal structures compared to ca. $10 \%$ of healthy controls. A further analysis revealed that those patients did not have autoantibodies against hypocretin, but against hypothalamic glutamic acidisoleucine/ $\alpha$-melanocyte-stimulating hormone (NEI/ $\alpha \mathrm{MSH}$ ), GABAergic cortical interneurons, and globus pallidus neurons [53•]. In the hypothalamus, cells expressing NEI/ $\alpha \mathrm{MSH}$ are adjacent to hypocretin neurons. Administration of NEI/ $\alpha \mathrm{MSH}$ autoantibody-positive immunoglobulins into a rat CNS, as in the case of anti-TRIB2 antibodies (see above), led to neurological symptoms and altered sleep pattern [53•].

It was puzzling that the increased frequency of narcolepsy was associated with the European Pandemrix vaccine and to a much lesser extent, if at all, with Arepanrix, which was used in Canada $[2 \bullet \cdot, 54]$. Since the AS03 adjuvant used in both vaccines was produced in the same European factory, the differences between Pandemrix and Arepanrix are solely in the H1N1 influenza virus antigen preparation used in the different vaccines. Vaarala and coworkers showed that the viral nucleoprotein (NP) concentration, including polymeric NP, was higher in Pandemrix than in Arepanrix [30••]. In addition, immune response against NP was higher in narcoleptic Pandemrix-vaccinated children than in healthy, matched control individuals vaccinated with Pandemrix [30・•]. Furthermore, antigen absorption experiments pointed out that the antigen compositions of Pandemrix and Arepanrix are immunologically different, but the contribution of these differences in the development of narcolepsy remains elusive. A more recent study also confirmed certain differences in protein composition and modifications between viral antigens in Pandemrix and Arepanrix [55].

Molecular mimicry and cross-reactivity between microbial components and host proteins/molecules may contribute to the development of autoimmune diseases. A National Center for Biotechnology Information search for potential crossreactive epitopes between Pandemrix viral antigens and host components led to the identification of a potentially crossreactive epitope between influenza NP and human hypocretin receptor 2 (HCRTR2) [31]. Antibodies against an NP epitope, which cross-reacted with a similar epitope from human HCRTR2, were found in sera collected from children and adolescents who developed narcolepsy after the vaccination with Pandemrix. The epitope contained seven identical amino acids within a 20 -amino-acid-long structure. Peptide absorption experiments confirmed the specificity of autoantibodies 
against the common epitope between NP and HCRTR2 [31]. Nonetheless, sera collected from non-narcoleptic children prior to the 2009 influenza pandemic also showed some autoimmunity against the cross-reactive epitopes. This raises some concern regarding the specificity of this cross-reaction as a causative mechanism in Pandemrix-associated narcolepsy. Moreover, recent studies demonstrated no anti-HCRTR2specific antibodies or a low titer and a very low frequency of these antibodies in narcoleptic children, suggesting that this type of autoantibody formation is likely not a general feature of childhood narcolepsy [56, 57]. The situation has recently become even more complex with the identification of neurexin-1, methyltransferase-like 22 (METTL22), 5'-nucleotidase cytosolic IA (NT5C1A) proteins, and the prostaglandin D2 receptor being potential autoantigens in narcolepsy. Patient sera from Pandemrix-associated narcolepsy patients showed a higher frequency of antibodies against various epitopes of those proteins $[44,58 \cdot, 59 \cdot]$. However, control individuals without narcolepsy also showed some autoimmunity against these proteins.

Numerous studies suggest that the onset of narcolepsy is genetically linked to several genes, with the HLA class II system manifesting the highest impact, which implies a role for cell-mediated immunity in narcolepsy. In addition, various types of autoantibodies with specificity to hypothalamic cells and neuronal proteins and peptides propose that humoral immunity, too, may contribute to the pathogenesis of narcolepsy. However, these findings could also be partly explained by a consequence or a downstream effect of local neuronal cell death, followed by autoantibody formation. A general inflammatory response leading to enhanced cytotoxicity and neuronal damage in CNS is another potential mechanism assisting the onset of narcolepsy. Figure 1 illustrates the potential immune mechanisms contributing to narcolepsy.

There is no evidence of an association between any other influenza vaccine and narcolepsy. It is possible that there were other temporary factors, in addition to vaccination, that could have impaired self-tolerance at the same time. A concurrent influenza infection was discussed earlier. A Swedish group found an increased interferon-gamma production against beta-hemolytic group A streptococcus [60]. We may speculate that some other factors, such as streptococcal infections, may have impaired self-tolerance at the time of vaccination. Furthermore, it has been proposed that at least four other groups of people are at risk of having autoimmune-like symptoms after vaccinations: (a) patients with a history of previous post-vaccination autoimmune phenomena, (b) patients with a history of some other autoimmunity, (c) patients with a history of allergic reactions, and (d) individuals who are prone to develop autoimmunity (positive family history of autoimmune diseases, presence of HLA DQB1*06:02 and/or absence of HLA DQB1*06:03, etc.) [61]. The latter suggestion is indirectly supported by findings from our original patient series, where $17 \%$ of patients with Pandemrix-related narcolepsy had a history of asthma or atopy, and all patients were positive for HLA DQB $1 * 06: 02$ [18••]. A similar connection was reported in a Spanish study, in which $19 \%$ of narcoleptic patients had one or more associated immune-mediated diseases (odds ratio 3.17 compared to general population) [62]. In contrast, in a French study, only $4.9 \%$ of NT1 patients had a comorbid autoimmune disease, which is an equal prevalence compared to the general population [63]. In this study, comorbid autoimmune diseases were more prevalent in idiopathic hypersomnia and NT2 than in NT1 [63].

\section{Clinical Description-Are There Any Differences Between Pandemrix-Related and Idiopathic Narcolepsy?}

Some interesting differences have been reported in the clinical features of Pandemrix-related narcolepsy and non-vaccine-associated narcolepsy [64, 65•]. In our experience, Pandemrix-related NT1 was often characterized by a rapid onset and short delay between the onset of symptoms and diagnosis. A more abrupt onset in Pandemrixassociated narcolepsy has also been reported in other studies $[18 \bullet \bullet, 65 \bullet, 66-68]$.

Facial hypotonia and "cataplectic facies" are increasingly recognized features in childhood cataplexy. Facial hypotonia and tongue protrusion were reported to be more common in children with Pandemrix-related narcolepsy than in those with idiopathic narcolepsy [68]. The incidence of childhood narcolepsy peaks among 10-20-year-olds and an early onset in preschool-aged children is very rare. One striking feature of vaccine-associated narcolepsy was the emergence of cases also at preschool age $[7 \bullet \bullet, 18 \bullet \bullet, 67,69]$. On the other hand, a few studies have reported a higher mean age at the time of diagnosis or onset of symptoms in Pandemrix-associated narcolepsy $[18 \bullet \bullet, 64]$.

In a comparison between unvaccinated Italian and vaccinated Finnish children with narcolepsy, no significant differences were seen, except for more disturbed sleep characteristics in Finnish subjects [64]. Even if the onset were more abrupt, the fully developed clinical picture of Pandemrixassociated narcolepsy seems to be very similar to idiopathic narcolepsy [65•]. However, the clinical picture of NT1 is very heterogeneous. Some subjects with Pandemrixassociated NT1 may manage even without any medication and be able to fully continue to work or study, while others are severely handicapped [65 ${ }^{\circ}$. Objective polysomnographic and actigraphic characteristics seem to be very similar between vaccine- and non-vaccine-associated narcolepsy [70]. There were some differences in sleep-wake rhythm parameters implying an earlier sleep phase in Pandemrixassociated narcolepsy [70]. 


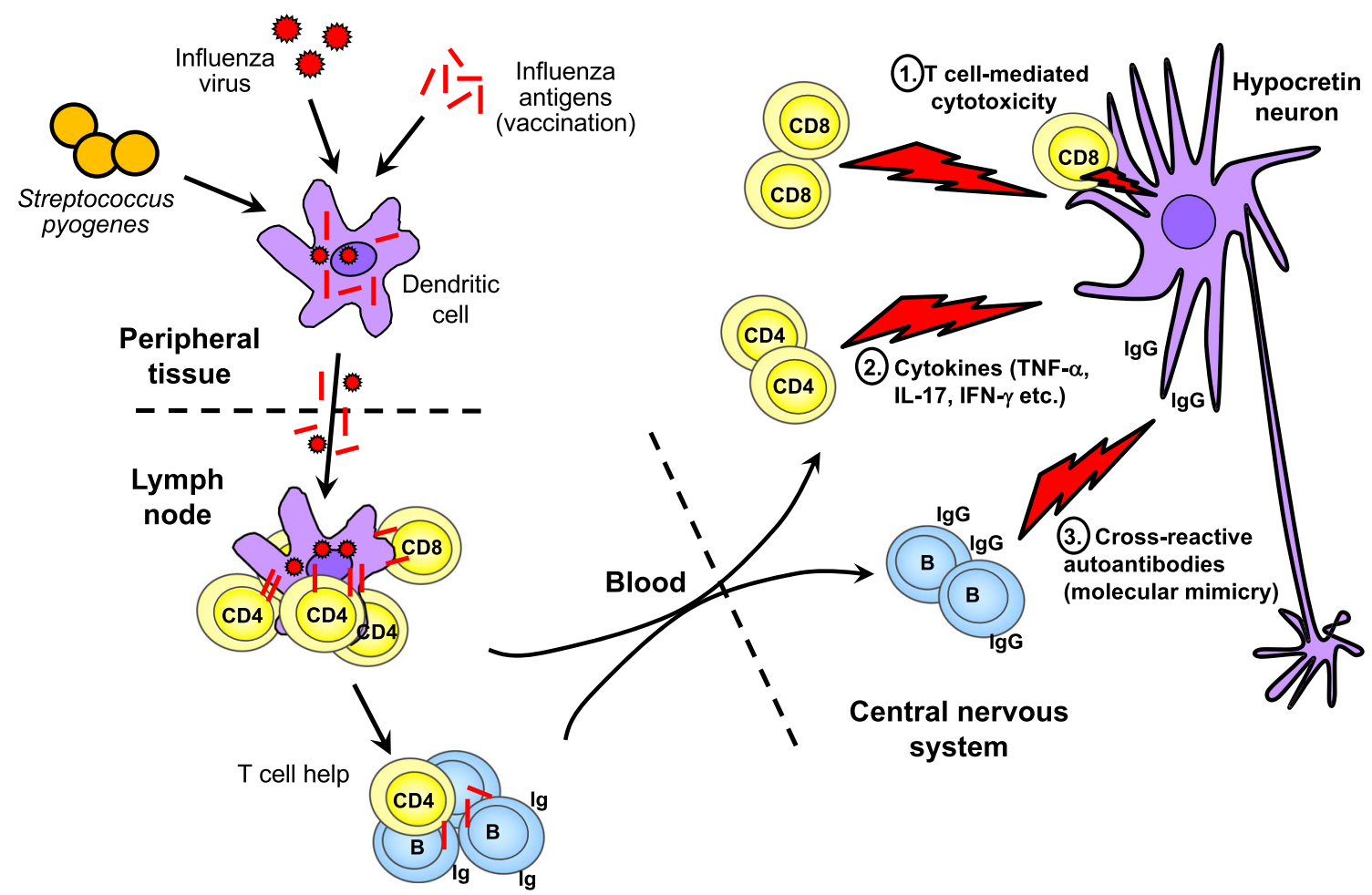

Fig. 1 A hypothetical model of autoimmunity in narcolepsy induced by influenza A virus infection or vaccination or streptococcal infection. Influenza A virus infection (or S. pyogenes infection) or vaccination with AS03-adjuvanted pandemic influenza vaccine leads to an infection or an uptake of viral antigens by dendritic cells (DCs) in peripheral tissues. This leads to the maturation and migration of infected or antigen-loaded DCs to local lymph nodes. In the lymph nodes, DCs present influenza-specific epitopes to CD4- and CD8-positive T cells. CD4 helper T cells provide help and activation of $\mathrm{B}$ cells that have also taken up soluble viral antigens. Activated T cells and matured IgG-

We have seen some, fortunately only a few, Pandemrixassociated NT1 subjects developing very severe psychiatric symptoms. Some of these psychiatric symptoms are so devastating that they resemble psychosis, Klüver-Bucy syndrome, or autoimmune encephalitis. We have screened for a large repertoire of neuronal autoantibodies in these patients but failed to find any conclusive evidence for a CNSspecific autoimmunity.

\section{Treatment}

Symptomatic treatment of Pandemrix-associated narcolepsy mirrors the treatment of idiopathic narcolepsy using, for example, modafinil, methylphenidate, and sodium oxybate. Immunomodulatory treatment has not proven to be effective in the treatment of Pandemrix-related narcolepsy but the evidence is limited. We have experience of five Finnish postPandemrix patients with intravenous immunoglobulin (IVIg) treatment administered within a few months of the disease onset. None of the patients benefited from the treatment. producing B cells migrate via blood into the central nervous system. In the brain, in the event that cross-reactive cell-mediated and humoral immunity has developed, autoimmunity is involved in the destruction of hypocretin-producing neurons in the hypothalamus. Potentially, three mechanisms may be involved: (1) activated CD8 T cells destroy neurons via cytotoxic mechanisms; (2) inflammatory cytokines, produced by activated $\mathrm{T}$ cells, induce cellular cytotoxicity; or (3) autoantibodies, which recognize cross-reactive epitopes on neurons, induce antibodydependent cytotoxicity

Danish colleagues have reported similar results [71]. One recent report suggested that an early combined immunotherapy with methylprednisolone and IVIg may have had a positive effect on relieving symptoms, but the results have to be taken cautiously since we know that the natural course of narcolepsy is very heterogeneous $[65 \cdot, 72]$.

There is a case report that provides a spark of hope for immune therapy in narcolepsy [73]. The authors demonstrated the normalization of hypocretin levels and remission of sleepiness and cataplexy in a patient treated with IVIg very early after the symptom onset [73]. Unfortunately, the treatment effect lasted only for a few months and the subject refused further treatment. We have reported a patient with a dramatic, but again unfortunately temporary, improvement of symptoms after treatment with rituximab [74]. The largest study so far on the immunomodulatory treatment in pediatric narcolepsy is a non-randomized controlled open-label trial in France [75]. In this study, a subset of patients with the highest scores in the narcolepsy screening questionnaire Ullanlinna Narcolepsy Scale (UNS) had remission of symptoms sooner than those who were not treated with IVIg. 
Taken together, the attempts to utilize immunomodulatory treatment in narcolepsy have provided controversial results. It is possible that immune therapies should be administered very soon after the disease onset, before the permanent damage to hypocretin system has taken place. The pathogenic cascade leading to narcolepsy may begin months or even years before the actual symptoms emerge; thus, in the majority of cases, it may already be too late when the patient enters the clinic. A multicenter randomized controlled trial of immunotherapy near the disease onset might provide an answer to this question. In the future, once the autoantigens have been identified and the disease mechanisms resolved, immune therapy may become an efficient therapy.

\section{Conclusions}

Several studies from different countries using alternative methods have confirmed the association between narcolepsy and Pandemrix vaccination. This provides strong evidence of a true association even if the possible diagnostic biases may somewhat reduce the risk. The classic criteria for an autoimmune disease are not fully met in the case of narcolepsy, but increasing evidence suggests an immune-mediated mechanism in the disease pathogenesis. It is also important to state that seasonal influenza vaccines, which are given to hundreds of millions of individuals every year, have not been associated with narcolepsy.

Research on narcolepsy was remarkably enhanced after Pandemrix-related narcolepsy was identified in 2010 and the work, for good reason, continues intensively. A conclusive explanation for the disease mechanism(s) has still remained elusive. Hopefully, active research efforts on understanding its pathogenesis may lead to the revelation of the etiology of narcolepsy, which provides us with better means to prevent similar events in the future. There is also a great demand for novel immunotherapeutic and other treatment modalities.

Acknowledgments We thank Damon Tringham for linguistic advice.

\section{Compliance with Ethical Standards}

Conflict of Interest Tomi Sarkanen reports a grant from The Finnish Medical Council, personal fees from Orion, and travel expenses from UCB, outside the submitted work.

Anniina Alakuijala reports no conflict of interest.

Ilkka Julkunen reports a research grant from the Academy of Finland, outside the submitted work.

Markku Partinen reports research grants from the Academy of Finland, personal fees from UCB-Pharma, GSK, Takeda, MSD, Orion, and participating in clinical trials by Bioprojet, Jazz Pharmaceuticals, and MSD, all outside the submitted work.

Human and Animal Rights and Informed Consent This article does not contain any studies with human or animal subjects performed by any of the authors.

\section{References}

Papers of particular interest, published recently, have been highlighted as:

- Of importance

- Of major importance

1. American Academy of Sleep Medicine. International classification of sleep disorders. 3rd ed. Darien: American Academy of Sleep Medicine; 2014.

2.• Sarkanen T, Alakuijala A, Dauvilliers Y, Partinen M. Incidence of narcolepsy after H1N1 influenza and vaccinations: systematic review and meta-analysis. Sleep Med Rev. 2017; https://doi.org/10. 1016/j.smrv.2017.06.006. A comprehensive review and metaanalysis of the observational studies reporting an association with Pandemrix and narcolepsy. In addition, biases affecting the risk and lack of an association with other vaccines and narcolepsy are discussed.

3. Partinen M, Kornum BR, Plazzi G, Jennum P, Julkunen I, Vaarala $\mathrm{O}$. Narcolepsy as an autoimmune disease: the role of H1N1 infection and vaccination. Lancet Neurol. 2014;13(6):600-13.

4. Dominguez-Cherit G, Lapinsky SE, Macias AE, Pinto R, EspinosaPerez L, de la Torre A, et al. Critically ill patients with 2009 influenza $\mathrm{A}(\mathrm{H} 1 \mathrm{~N} 1)$ in Mexico. JAMA. 2009;302(17):1880-7.

5. European Centre for Disease Prevention and Control. Narcolepsy in association with pandemic influenza vaccination (a multi-country European epidemiological investigation). Stockholm 2012. https:// ecdc.europa.eu/sites/portal/files/media/en/publications/ Publications/Vaesco\%20report\%20FINAL\%20with\%20cover.pdf. Accessed 13 Nov 2017.

6. GlaxoSmithKline. GSK Public policy positions. Pandemic preparedness. 2014. https://www.gsk.com/media/2951/pandemicpreparedness-policy.pdf. Accessed 13 Nov 2017.

7.• Nohynek H, Jokinen J, Partinen M, Vaarala O, Kirjavainen T, Sundman J, et al. AS03 adjuvanted AH1N1 vaccine associated with an abrupt increase in the incidence of childhood narcolepsy in Finland. PLoS One. 2012;7(3):e33536. The first epidemiological study reporting an increased incidence of narcolepsy after vaccination with Pandemrix.

8. Medical Products Agency. A registry based comparative cohort study in four Swedish counties of the risk for narcolepsy after vaccination with Pandemrix - a first and preliminary report. 2011. https://lakemedelsverket.se/upload/nyheter/2011/ PandemrixRegReport110328.pdf. Accessed 13 Nov 2017.

9. Dauvilliers Y, Arnulf I, Lecendreux M, Monaca Charley C, Franco $\mathrm{P}$, Drouot $\mathrm{X}$, et al. Increased risk of narcolepsy in children and adults after pandemic H1N1 vaccination in France. Brain. 2013;136(Pt 8):2486-96.

10. Heier MS, Gautvik KM, Wannag E, Bronder KH, Midtlyng E, Kamaleri Y, et al. Incidence of narcolepsy in Norwegian children and adolescents after vaccination against H1N1 influenza A. Sleep Med. 2013;14(9):867-71.

11. Miller E, Andrews N, Stellitano L, Stowe J, Winstone AM, Shneerson J, et al. Risk of narcolepsy in children and young people receiving AS03 adjuvanted pandemic A/H1N1 2009 influenza vaccine: retrospective analysis. BMJ. 2013;346:f794.

12. O'Flanagan D, Barret AS, Foley M, Cotter S, Bonner C, Crowe C, et al. Investigation of an association between onset of narcolepsy and vaccination with pandemic influenza vaccine, Ireland April 2009-December 2010. Euro Surveill. 2014;19(17):15-25.

13. Oberle D, Pavel J, Mayer G, Geisler P, Keller-Stanislawski B. Retrospective multicenter matched case-control study on the risk factors for narcolepsy with special focus on vaccinations (including 
pandemic influenza vaccination) and infections in Germany. Sleep Med. 2017;34:71-83.

14. Jokinen J, Nohynek H, Honkanen J, Vaarala O, Partinen M, Hublin C et al. Pandemiarokotteen ja narkolepsian yhteys aikuisilla Varmennettuihin rekisteritietoihin perustuva kohorttitutkimus. 2013. http://urn.fi/URN:ISBN:978-952-245-921-3. Accessed 13 Nov 2017.

15. Persson I, Granath F, Askling J, Ludvigsson JF, Olsson T, Feltelius N. Risks of neurological and immune-related diseases, including narcolepsy, after vaccination with Pandemrix: a population- and registry-based cohort study with over 2 years of follow-up. J Intern Med. 2014;275(2):172-90.

16. Stowe J, Miller E, Andrews N, Kosky C, Leschziner G, Shneerson $\mathrm{JM}$, et al. Risk of narcolepsy after AS03 adjuvanted pandemic A/ H1N1 2009 influenza vaccine in adults: a case-coverage study in England. Sleep. 2016;39(5):1051-7.

17. Jokinen J, Nohynek H, Vaarala O, Kilpi T. Pandemiarokotteen ja narkolepsian yhteys - vuoden 2012 loppuun mennessä kertyneisiin rekisteritietoihin perustuva seurantaraportti. 2014. http://urn.fi/ URN:ISBN:978-952-302-255-3. Accessed 13 Nov 2017.

18.• Partinen M, Saarenpaa-Heikkila O, Ilveskoski I, Hublin C, Linna M, Olsen $\mathrm{P}$, et al. Increased incidence and clinical picture of childhood narcolepsy following the $2009 \mathrm{H} 1 \mathrm{~N} 1$ pandemic vaccination campaign in Finland. PLoS One. 2012;7(3):e33723. The first article reporting the clinical picture and increased incidence of narcolepsy after vaccination with Pandemrix in the Nordic countries.

19. Verstraeten T, Cohet C, Santos GD, Ferreira GL, Bollaerts K, Bauchau $\mathrm{V}$, et al. Pandemrix and narcolepsy: a critical appraisal of the observational studies. Hum Vaccin Immunother. 2016;12(1):187-93.

20. Bollaerts K, Shinde V, Dos Santos G, Ferreira G, Bauchau V, Cohet $\mathrm{C}$, et al. Application of probabilistic multiple-bias analyses to a cohort- and a case-control study on the association between Pandemrix and narcolepsy. PLoS One. 2016;11(2):e0149289.

21. Sturkenboom MCJM. The narcolepsy-pandemic influenza story: can the truth ever be unraveled? Vaccine. 2015;33(Supplement 2):B6-B13.

22. Han F, Lin L, Warby SC, Faraco J, Li J, Dong SX, et al. Narcolepsy onset is seasonal and increased following the $2009 \mathrm{H} 1 \mathrm{~N} 1$ pandemic in China. Ann Neurol. 2011;70(3):410-7. The authors report a 3fold increase of narcolepsy in the Beijing area in China where no pandemic vaccines were used. A similar finding was seen in the Shanghai area, but not in any other country.

23. Han F, Lin L, Li J, Dong XS, Mignot E. Decreased incidence of childhood narcolepsy 2 years after the 2009 H1N1 winter flu pandemic. Ann Neurol. 2013;73(4):560.

24. Wu H, Zhuang J, Stone WS, Zhang L, Zhao Z, Wang Z, et al. Symptoms and occurrences of narcolepsy: a retrospective study of 162 patients during a 10-year period in eastern China. Sleep Med. 2014;15(6):607-13.

25. Choe YJ, Bae GR, Lee DH. No association between influenza A(H1N1)pdm09 vaccination and narcolepsy in South Korea: an ecological study. Vaccine. 2012;30(52):7439-42.

26. Gil Cuesta J, Aavitsland P, Englund H, Gudlaugsson O, Hauge SH, Lyytikainen $\mathrm{O}$, et al. Pandemic vaccination strategies and influenza severe outcomes during the influenza $\mathrm{A}(\mathrm{H} 1 \mathrm{~N} 1) \mathrm{pdm} 09$ pandemic and the post-pandemic influenza season: the Nordic experience. Euro Surveill. 2016; https://doi.org/10.2807/1560-7917.ES.2016. 21.16.30208

27. Van Effelterre T, Dos Santos G, Shinde V. Twin peaks: A/H1N1 pandemic influenza virus infection and vaccination in Norway, 2009-2010. PLoS One. 2016;11(3):e0151575.

28. Melen K, Partinen M, Tynell J, Sillanpaa M, Himanen SL, Saarenpaa-Heikkila $\mathrm{O}$, et al. No serological evidence of influenza A H1N1pdm09 virus infection as a contributing factor in childhood narcolepsy after Pandemrix vaccination campaign in Finland. PLoS One. 2013;8(8):e68402.

29. Innis B, Boutet P. Comment on: Melen K, Partinen M, Tynell J, Sillanpaa M, Himanen S-L, et al. No serological evidence of influenza A H1N1pdm09 virus infection as a contributing factor in childhood narcolepsy after pandemrix vaccination campaign in Finland. PLoS One. 2014. http://journals.plos.org/plosone/article/ comment?id=10.1371/annotation/eab58001-4872-4b9d-94d7c85a16b4b6d6. Accessed 13 Nov 2017.

30.• Vaarala O, Vuorela A, Partinen M, Baumann M, Freitag TL, Meri $\mathrm{S}$, et al. Antigenic differences between AS03 adjuvanted influenza A (H1N1) pandemic vaccines: implications for Pandemrixassociated narcolepsy risk. PLoS One. 2014;9(12):e114361. A study reporting differences in nucleoprotein (NP) of the viral component in Pandemrix and Arepanrix. Furthermore, increased antibody response against NP was seen in subjects with the HLA DQB1*06:02 narcolepsy risk allele.

31. Ahmed SS, Volkmuth W, Duca J, Corti L, Pallaoro M, Pezzicoli A, et al. Antibodies to influenza nucleoprotein cross-react with human hypocretin receptor 2. Sci Transl Med. 2015;7(294):294ra105.

32. Tesoriero C, Codita A, Zhang MD, Cherninsky A, Karlsson H, Grassi-Zucconi G, et al. H1N1 influenza virus induces narcolepsy-like sleep disruption and targets sleep-wake regulatory neurons in mice. Proc Natl Acad Sci U S A. 2016;113(3):E368-77.

33. Sakurai T, Amemiya A, Ishii M, Matsuzaki I, Chemelli RM, Tanaka $\mathrm{H}$, et al. Orexins and orexin receptors: a family of hypothalamic neuropeptides and $g$ protein-coupled receptors that regulate feeding behavior. Cell. 1998;92:573-85.

34. de Lecea L, Kilduff TS, Peyron C, Gao X, Foye PE, Danielson PE, et al. The hypocretins: hypothalamus-specific peptides with neuroexcitatory activity. Proc Natl Acad Sci U S A. 1998;95(1):322-7.

35. Peyron C, Faraco J, Rogers W, Ripley B, Overeem S, Charnay Y, et al. A mutation in a case of early onset narcolepsy and a generalized absence of hypocretin peptides in human narcoleptic brains. Nat Med. 2000;6(9):991-7.

36. Julkunen I, Partinen M. Neuroimmunology: disease mechanisms in narcolepsy remain elusive. Nat Rev Neurol. 2014;10(11):616-7.

37. Nishino S, Kanbayashi T. Symptomatic narcolepsy, cataplexy and hypersomnia, and their implications in the hypothalamic hypocretin/orexin system. Sleep Med Rev. 2005;9(4):269-310.

38. Tafti M, Hor H, Dauvilliers Y, Lammers GJ, Overeem S, Mayer G, et al. DQB1 locus alone explains most of the risk and protection in narcolepsy with cataplexy in Europe. Sleep. 2014;37(1):19-25. A large genome-wide association (GWAS) study with over 1200 narcolepsy patients and 3500 controls. It was shown that the majority of the genetic risk of narcolepsy is explained by the HLA DQB1 locus only. HLA DQB1*06:02 positive individuals carry a 251-fold increased risk of developing narcolepsy.

39. Hor H, Bartesaghi L, Kutalik Z, Vicario JL, de Andres C, Pfister C, et al. A missense mutation in myelin oligodendrocyte glycoprotein as a cause of familial narcolepsy with cataplexy. Am J Hum Gen. 2011;89(3):474-9.

40. Mignot E, Lin L, Rogers W, Honda Y, Qiu X, Lin X, et al. Complex HLA-DR and -DQ interactions confer risk of narcolepsy-cataplexy in three ethnic groups. Am J Hum Gen. 2001;68(3):686-99.

41. Ollila HM, Ravel JM, Han F, et al. HLA-DPB1 and HLA class I confer risk of and protection from narcolepsy. Am J Hum Genet. 2015;96:136-46. One of the first reports to find HLA class I associations in narcolepsy.

42. Tafti M, Lammers GJ, Dauvilliers Y, et al. Narcolepsy-associated HLA class I alleles implicate cell-mediated cytotoxicity. Sleep. 2016;39:581-7. One of the first reports to find HLA class I associations in narcolepsy.

43. Aran A, Lin L, Nevsimalova S, Plazzi G, Hong SC, Weiner K, et al. Elevated anti-streptococcal antibodies in patients with recent narcolepsy onset. Sleep. 2009;32(8):979-83.

44. Haggmark-Manberg A, Zandian A, Forsstrom B, Khademi M, Lima Bomfim I, Hellstrom C, et al. Autoantibody targets in vaccine-associated narcolepsy. Autoimmunity. 2016;49(6):421-33. 
45. Saariaho AH, Vuorela A, Freitag TL, Pizza F, Plazzi G, Partinen M, et al. Autoantibodies against ganglioside GM3 are associated with narcolepsy-cataplexy developing after Pandemrix vaccination against 2009 pandemic H1N1 type influenza virus. J Autoimmun. 2015;63:68-75.

46. Cvetkovic-Lopes V, Bayer L, Dorsaz S, Maret S, Pradervand S, Dauvilliers Y, et al. Elevated Tribbles homolog 2-specific antibody levels in narcolepsy patients. J Clin Invest. 2010;120(3):713-9.

47. Kawashima M, Lin L, Tanaka S, Jennum P, Knudsen S, Nevsimalova S, et al. Anti-Tribbles homolog 2 (TRIB2) autoantibodies in narcolepsy are associated with recent onset of cataplexy. Sleep. 2010;33(7):869-74.

48. Katzav A, Arango MT, Kivity S, Tanaka S, Givaty G, AgmonLevin N, et al. Passive transfer of narcolepsy: anti-TRIB2 autoantibody positive patient $\operatorname{IgG}$ causes hypothalamic orexin neuron loss and sleep attacks in mice. J Autoimmun. 2013;45:24-30.

49. Lind A, Ramelius A, Olsson T, Arnheim-Dahlstrom L, Lamb F, Khademi M, et al. A/H1N1 antibodies and TRIB2 autoantibodies in narcolepsy patients diagnosed in conjunction with the Pandemrix vaccination campaign in Sweden 2009-2010. J Autoimmun. 2014;50:99-106.

50. Tanaka S, Honda Y, Honda M, Yamada H, Honda K, Kodama T. Anti-tribbles pseudokinase 2 (TRIB2)-immunization modulates hypocretin/orexin neuronal functions. Sleep. 2017; https://doi.org/ 10.1093/sleep/zsw036.

51. Goodfellow JA, Willison HJ. Antiganglioside, antigangliosidecomplex, and antiglycolipid-complex antibodies in immunemediated neuropathies. Curr Opin Neurol. 2016;29(5):572-80.

52. Overeem S, Geleijns K, Garssen MP, Jacobs BC, van Doorn PA, Lammers GJ. Screening for anti-ganglioside antibodies in hypocretindeficient human narcolepsy. Neurosci Lett. 2003;341(1):13-6.

53. Bergman P, Adori C, Vas S, Kai-Larsen Y, Sarkanen T, Cederlund A, et al. Narcolepsy patients have antibodies that stain distinct cell populations in rat brain and influence sleep patterns. Proc Natl Acad Sci U S A. 2014;111(35):E3735-44. In this study, 27\% of narcolepsy patients showed autoantibodies against three different neuronal structures in immunohistochemical stainings on rat brain. Although staining against hypocretin neurons was not seen, autoantibodies against hypothalamic NEI/ $\alpha$ MSH neurons were found. Passive transfer of sera from NEI/ $\alpha \mathrm{MSH}-$ positive subject into a rat brain produced disturbed REM and slow wave sleep patterns.

54. Montplaisir J, Petit D, Quinn M-J, Ouakki M, Deceuninck G, Desautels A, et al. Risk of narcolepsy associated with inactivated adjuvanted (AS03) A/H1N1 (2009) pandemic influenza vaccine in Quebec. PLoS One. 2014;9(9):e108489.

55. Jacob L, Leib R, Ollila HM, Bonvalet M, Adams CM, Mignot E. Comparison of Pandemrix and Arepanrix, two pH1N1 AS03adjuvanted vaccines differentially associated with narcolepsy development. Brain Behav Immun. 2015;47:44-57.

56. Luo G, Lin L, Jacob L, Bonvalet M, Ambati A, Plazzi G, et al. Absence of anti-hypocretin receptor 2 autoantibodies in post pandemrix narcolepsy cases. PLoS ONE. 12(12):e0187305. https://doi.org/10.1371/journal.pone.0187305.

57. Giannoccaro MP, Waters P, Pizza F, Liguori R, Plazzi G, Vincent A. Antibodies against hypocretin receptor 2 are rare in narcolepsy. Sleep. 2017;40 https://doi.org/10.1093/sleep/zsw056.

58. Zandian A, Forsstrom B, Haggmark-Manberg A, Schwenk JM, Uhlen M, Nilsson P, et al. Whole-proteome peptide microarrays for profiling autoantibody repertoires within multiple sclerosis and narcolepsy. J Proteome Res. 2017;16(3):1300-14. The authors presented a novel method for screening autoantibodies, namely high-density peptide arrays. They recognized a potential new autoantigen neurexin 1 in narcolepsy.

59. Sadam H, Pihlak A, Kivil A, Pihelgas S, Jaago M, Adler P, et al. Prostaglandin D2 receptor DP1 antibodies predict vaccine-induced and spontaneous narcolepsy type 1: large-scale study of antibody profiling. EBioMedicine. 2018;29:47-59. The authors describe a potentially new autoantigen prostaglandin D2 receptor against which narcolepsy patient have developed autoantibodies.

60. Ambati A, Poiret T, Svahn BM, Valentini D, Khademi M, Kockum I, et al. Increased beta-haemolytic group A streptococcal M6 serotype and streptodornase B-specific cellular immune responses in Swedish narcolepsy cases. J Intern Med. 2015;278(3):264-76.

61. Soriano A, Nesher G, Shoenfeld Y. Predicting post-vaccination autoimmunity: who might be at risk? Pharmacol Res. 2015;92:18-22.

62. Martinez-Orozco FJ, Vicario JL, Villalibre-Valderrey I, De Andres C, Fernandez-Arquero M, Peraita-Adrados R. Narcolepsy with cataplexy and comorbid immunopathological diseases. J Sleep Res. 2014;23(4):414-9.

63. Barateau L, Lopez R, Arnulf I, Lecendreux M, Franco P, Drouot X, et al. Comorbidity between central disorders of hypersomnolence and immune-based disorders. Neurology. 2017;88(1):93-100.

64. Pizza F, Peltola H, Sarkanen T, Moghadam KK, Plazzi G, Partinen M. Childhood narcolepsy with cataplexy: comparison between post-H1N1 vaccination and sporadic cases. Sleep Med. 2013;15(2):262-5.

65. Sarkanen T, Alakuijala A, Partinen M. Clinical course of H1N1vaccine-related narcolepsy. Sleep Med. 2016;19:17-22. The first longitudinal study of the clinical phenotype of Pandemrixrelated narcolepsy. The symptoms of narcolepsy and severity of the disease seem very heterogeneous.

66. Szakacs A, Darin N, Hallbook T. Increased childhood incidence of narcolepsy in western Sweden after H1N1 influenza vaccination. Neurology. 2013;80(14):1315-21.

67. Medical Products Agency. Occurrence of narcolepsy with cataplexy among children and adolescents in relation to the H1N1 pandemic and Pandemrix vaccinations - results of a case inventory study by the MPA in Sweden during 2009-2010. https:// lakemedelsverket.se/upload/nyheter/2011/Fallinventeringsrapport pandermrix_110630.pdf. Accessed 13 Nov 2017.

68. Winstone AM, Stellitano L, Verity C, Andrews N, Miller E, Stowe $\mathrm{J}$, et al. Clinical features of narcolepsy in children vaccinated with AS03 adjuvanted pandemic A/H1N1 2009 influenza vaccine in England. Dev Med Child Neurol. 2014;56(11):1117-23.

69. ECDC comment. Update on narcolepsy cases associated with Pandemrix vaccination in 2009 in the Netherlands. https://ecdc. europa.eu/en/news-events/update-narcolepsy-cases-associatedpandemrix-vaccination-2009-netherlands. Accessed 13 Nov 2017.

70. Alakuijala A, Sarkanen T, Partinen M. Polysomnographic and actigraphic characteristics of patients with H1N1-vaccine-related and sporadic narcolepsy. Sleep Med. 2015;16(1):39-44.

71. Knudsen S, Biering-Sorensen B, Kornum BR, Petersen ER, Petersen ER, Ibsen JD, et al. Early IVIg treatment has no effect on post-H1N1 narcolepsy phenotype or hypocretin deficiency. Neurology. 2012;79(1):102-3.

72. Viste R, Soosai J, Vikin T, Thorsby PM, Nilsen KB, Knudsen S. Long-term improvement after combined immunomodulation in early post-H1N1 vaccination narcolepsy. Neurol Neuroimmunol Neuroinflamm. 2017;4(5):e389.

73. Dauvilliers Y, Abril B, Mas E, Michel F, Tafti M. Normalization of hypocretin-1 in narcolepsy after intravenous immunoglobulin treatment. Neurology. 2009;73(16):1333-4.

74. Sarkanen T, Alen R, Partinen M. Transient impact of rituximab in H1N1 vaccination-associated narcolepsy with severe psychiatric symptoms. Neurologist. 2016;21(5):85-6.

75. Lecendreux M, Berthier J, Corny J, Bourdon O, Dossier C, Delclaux C. Intravenous immunoglobulin therapy in pediatric narcolepsy: a nonrandomized, open-label, controlled, longitudinal observational study. J Clin Sleep Med. 2017;13(3):441-53. 